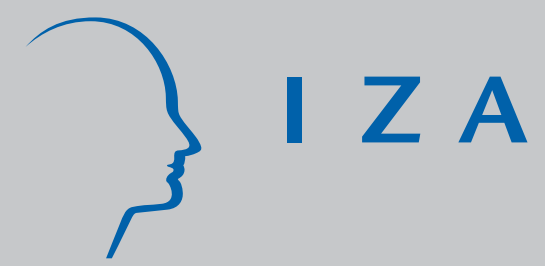

IZA DP No. 4863

Earnings Progression, Human Capital and Incentives: Theory and Evidence

Anders Frederiksen

April 2010 


\title{
Earnings Progression, Human Capital and Incentives: Theory and Evidence
}

\author{
Anders Frederiksen \\ CCP, Aarhus School of Business, \\ Aarhus University and IZA
}

Discussion Paper No. 4863

April 2010

IZA

P.O. Box 7240

53072 Bonn

Germany

Phone: +49-228-3894-0

Fax: +49-228-3894-180

E-mail: iza@iza.org

Any opinions expressed here are those of the author(s) and not those of IZA. Research published in this series may include views on policy, but the institute itself takes no institutional policy positions.

The Institute for the Study of Labor (IZA) in Bonn is a local and virtual international research center and a place of communication between science, politics and business. IZA is an independent nonprofit organization supported by Deutsche Post Foundation. The center is associated with the University of Bonn and offers a stimulating research environment through its international network, workshops and conferences, data service, project support, research visits and doctoral program. IZA engages in (i) original and internationally competitive research in all fields of labor economics, (ii) development of policy concepts, and (iii) dissemination of research results and concepts to the interested public.

IZA Discussion Papers often represent preliminary work and are circulated to encourage discussion. Citation of such a paper should account for its provisional character. A revised version may be available directly from the author. 
IZA Discussion Paper No. 4863

April 2010

\section{ABSTRACT \\ Earnings Progression, Human Capital and Incentives: Theory and Evidence*}

The career prospects of newly recruited employees differ substantially within an organization. The stars experience a considerable growth in earnings; others can hardly maintain their entry salaries. This article sheds light on the mechanisms generating the observed heterogeneity in earnings progression by investigating the effects of on-the-job human capital acquisition, explicit short-run incentives and career concern incentives on earnings progression. The model leads to predictions about the incentive structure and the progression in both cross-sectional and individual earnings which are supported by the empirical analysis based on personnel records from a large bank.

JEL Classification: J30, J41, M50

Keywords: explicit incentives, career concern incentives, performance, earnings dynamics, personnel economics

Corresponding author:

Anders Frederiksen

Department of Marketing and Statistics

Aarhus School of Business, Aarhus University

Haslegaarden

Haslegaardsvej 10

DK 8210 Aarhus V

Denmark

E-mail: afr@asb.dk

\footnotetext{
* I would like to thank Robert Gibbons, Alexander Koch, Bentley MacLeod, John Pencavel, Luigi Pistaferri, Kathryn Shaw, Elöd Takáts, Mike Waldman and seminar participants at Stanford University and the University of Hawaii at Manoa for helpful comments and discussions. Michael Lykke Jensen provided valuable research assistance. The Hoover Institution, Stanford University, kindly provided hospitality during the initial phase of this project.
} 


\section{Introduction}

The career prospects of newly hired employees differ substantially within an organization. The stars experience a considerable growth in earnings during the first years of employment; others can hardly maintain their entry salaries. Identifying the mechanisms generating this heterogeneity in pay progression is essential to understand behavior such as consumption and saving (Deaton, 1992) and to show the way to a successful labor market career.

In this paper, I investigate the implications of on-the-job human capital acquisition, short-run explicit incentives and career concern incentives for early career earnings progression. The employment relation is captured by a dynamic moral hazard model which is similar in nature to Gibbons and Murphy (1992) but allows for on-the-job human capital acquisition. Subsequently, the model's predictions are examined using personnel records from a large bank. While the stylized model imposes structure, the main contribution of the paper is the empirical application, which adds to the scant empirical literature on contracting. The innovation is to use detailed data on performance and the structure of earnings, i.e. separate information on base pay and bonus payments, to identify the dynamic incentive structure and the effect of on-the-job human capital acquisition on earnings. In turn, this provides detailed knowledge about the mechanisms leading to earnings progression.

The idea that earnings grow due to on-the-job human capital acquisitions has a long tradition in economics dating back to Becker (1964). Even though human capital theory explains a significant part of the progression in earnings, the literature emphasizes that no single theory is capable of explaining the complexity of earnings; see Baker, Gibbs and Holmström (1994a,b), and Gibbons and Waldman (1999a,b and 2003). One reason is that besides stimulating human capital accumulation, most employment matches are subject to moral hazard problems that have additional implications for earnings, see Mirrlees $(1974,1976)$ and Holmström $(1979,1982 \mathrm{a})$. This follows from the fact that employees can take action to affect the probability distribution of the performance outcome. In simple situations, the moral hazard problem can be solved by motivating the employee through explicit (short-run) incentives, i.e. by paying bonuses to high-performing employees. However, Fama (1980) noted that in a more general setting, the moral hazard problem is solved partly by career concern incentives where current performance is rewarded (or punished) in the future. An idea which was formalized later by Holmström (1982b, 1999). ${ }^{1}$

\footnotetext{
${ }^{1}$ See Borland (1992) for a survey of the literature.
} 
Following the literature, the theoretical model presented in this paper captures the idea that on-the-job human capital acquisition as well as incentives determine earnings progression. That is, despite employees becoming more productive over time as they learn on the job, they have to be incentivized to exert effort. In the present setup, employees are motivated both through short-run explicit incentives and career oriented incentives, which leads to a sophisticated trade-off between the different types of incentives. First, explicit bonus incentives increase with tenure to make up for the ongoing reduction in career concern incentives. Second, optimal incentives are balanced, such that total incentives (the sum of explicit bonus incentives and career concern incentives) are constant over an employee's career. Finally, if career concern incentives are sufficiently strong, explicit incentives are not needed early in an employee's career. Thus, the incentive trade-off combined with the effect of on-the-job human capital acquisition determine earnings progression.

The model also predicts the progression in both cross-sectional and individual earnings. First, the cross-sectional mean and variance of earnings increase with tenure. Second, individual earnings progression is highly volatile and heterogeneous. This is because an individual's earnings growth, in an incentive environment, is determined in part by individual performance. In fact, the model predicts that high-performance employees have positive earnings progression. In contrast, low-performance employees have relatively low earnings progression, and under certain conditions they experience a decline in real earnings.

Three important empirical results are established. First, in the investigated firm employees are incentivized by a combination of career oriented incentives and short-term explicit bonus incentives. This illustrates the complexity of motivating employees. As Holmström (1982b) shows, career oriented incentives are particularly strong early in the career, and only in the case where these incentives are insufficient, should they be complemented with explicit bonus incentives (Gibbons and Murphy, 1992). The fact that both types of incentives are used to motivate even newly recruited employees indicates that career concern incentives are insufficient to elicit the desired effort level.

Second, total incentives (the sum of explicit bonus incentives and career concern incentives) are balanced across an employee's career and at a level of 27 percent of first-year income. This result reflects that high performance early in the career is rewarded by bonuses, but also by the higher future pay that follows from career concern incentives. Later in the employment relation, the career oriented incentives are smaller (or absent), but higher bonus payments occur. In this respect, the empirically observed incentive 
contract matches the incentive contract derived from the theoretical model.

Third, on-the-job human capital acquisition is important for earnings progression and increases real earnings by 10.5 percent. But, as a consequence of the incentive structure, high performance employees have an expected real earnings growth of as much as 15.6 percent while low performance employees experience real earnings growths of only 6.1 percent. Thus, consistent with the model's predictions, it is established that both the cross-sectional mean and variance of earnings increase with tenure, and that variation in performance causes substantial heterogeneity in individual earnings progression.

In addition to identifying the consequences of on-the-job human capital acquisition and incentives for earnings progression, the findings presented in this paper also complement previous research on career concerns. Even though the theoretical literature in this area is extensive, only few studies have empirically identified career concern incentives and established their empirical consequences. One important paper combining theory and empirics is Gibbons and Murphy (1992), who identify career concerns among CEOs using late career dynamics. Another seminal paper by Chevalier and Ellison (1999) studies how incentives affect decision-making among mutual fund managers and identifies career concern incentives using data on employee turnover. $^{2}$ In the present paper, career concerns are identified from early career dynamics and, thus, focus is on a point in the employees' careers where the learning curve about their abilities is steep, see Farber and Gibbons (1996), Altonji and Pierret (2001), Lange (2007) and Frederiksen and Takats (2011). Further, the analysis exploits the detailed information conveyed in personnel records, and, thus, focus is on a very broad set of employees who, in principle, can be found in any organization. In this respect, the presented results may be more informative about career concerns in the general labor market than previous research in this area.

The current study is also related to the literature on earnings dynamics, see Lillard and Willis (1978), Lillard and Weiss (1979), MaCurdy (1982), Abowd and Card (1989), and Meghir and Pistaferri (2004). These papers identify the statistical properties of the earnings process and are highly sophisticated. But, the present study shows that this is also the case for the underlying mechanisms which generate the earnings process. For instance, it is documented that variation in performance play an important role for short-run volatility because high performance may lead to a bonus payment. It is also the case that individual performance manifests itself more perma-

\footnotetext{
${ }^{2}$ It should also be noted that a growing experimental literature is testing the importance and implications of career concern incentives, see Irlenbusch and Sliwka (2006) and Koch, Morgenstern and Raab (2009).
} 
nently in the earnings process because career concern incentives translate current performance into future pay.

The paper is structured as follows. The next section is dedicated to a preliminary inspection of the personnel records and a discussion of the institutional settings of the bank. In section 3, I present a theoretical model for earnings progression which incorporates on-the-job human capital acquisition, explicit bonus incentives and career concern incentives. The empirical results are provided in section 4 . Finally, a conclusion is presented in section 5.

\section{Earnings at work}

Before proceeding to the theoretical modelling of earnings progression and estimation, a description of the workplace and employment contracts as well as a presentation of some preliminary statistics on earnings may prove useful.

The data used in this analysis come from a large bank with more than 10,000 employees. The sample years are 2004 to 2008. Information has been obtained from the company's personnel records, which contain details about employee performance and earnings - and most importantly for this study - information on the composition of earnings, i.e. separate information on base pay and bonus payments. The measure of earnings used throughout the analysis is real annual earnings (in 2004-prices and measured in dollars), which is constructed as annual base pay plus bonuses obtained during the year.

Earnings progression differs substantially across employees. This can be seen in Figure 1, where the evolution in real earnings for the group of employees with one to five years of tenure is presented. First, median earnings and the standard deviation of earnings increase with tenure. Second, real earnings decline for some employees, but most employees experience positive earnings growth and some real earnings growths of as much as 15 percent per year. To illustrate why this picture emerges, examples of earnings growth for five different employees are presented in Figure 2. These examples illustrate that individual earnings tend to increase with tenure, but that the progression is highly volatile. In fact, it is a common feature that a year with substantial earnings growth is followed by a year with lower earnings.

\subsection{The empirical contract}

The contract the firm offers its employees transforms productivity into pay. In practice, the firm pays its employees a base salary each period and rewards 


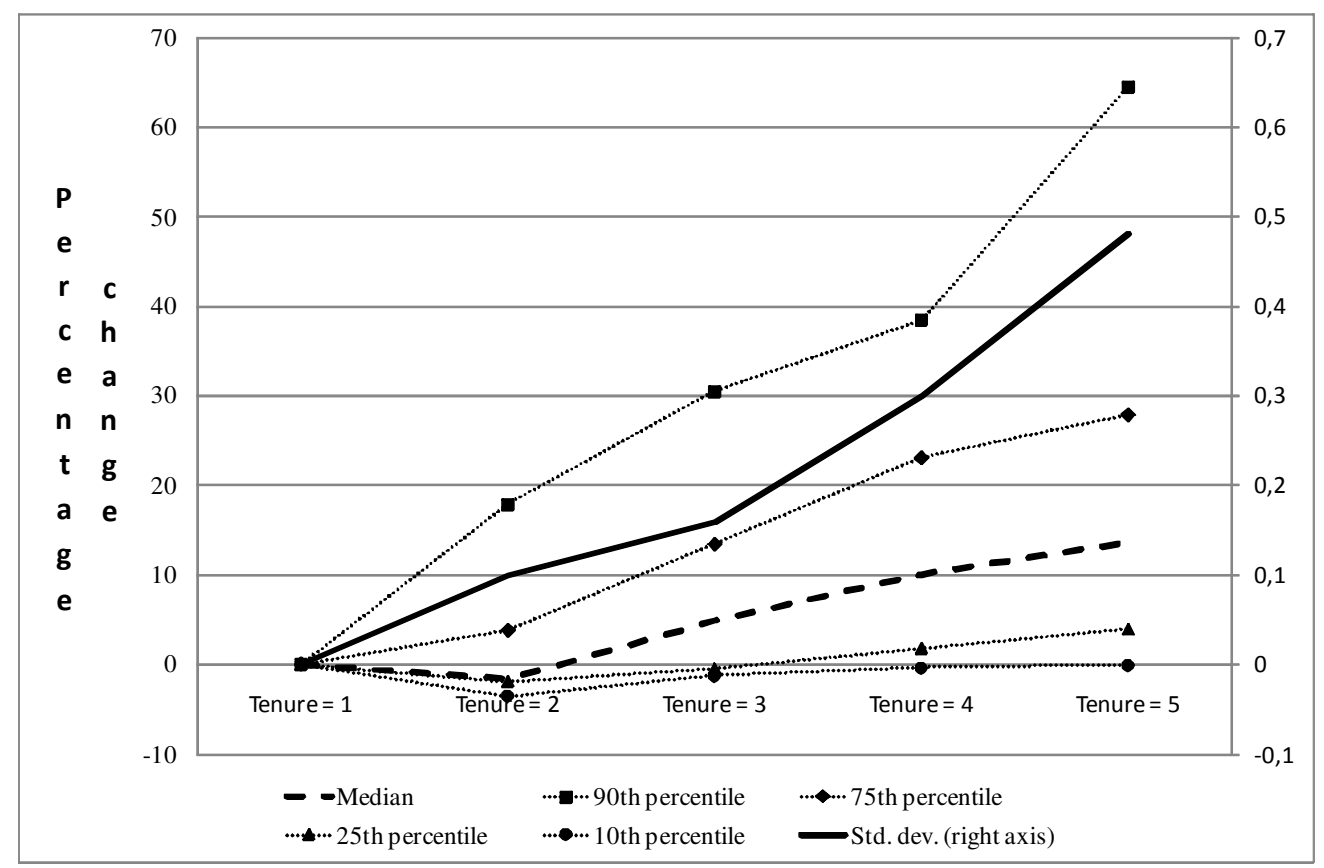

Figure 1: Cross-sectional earnings progression

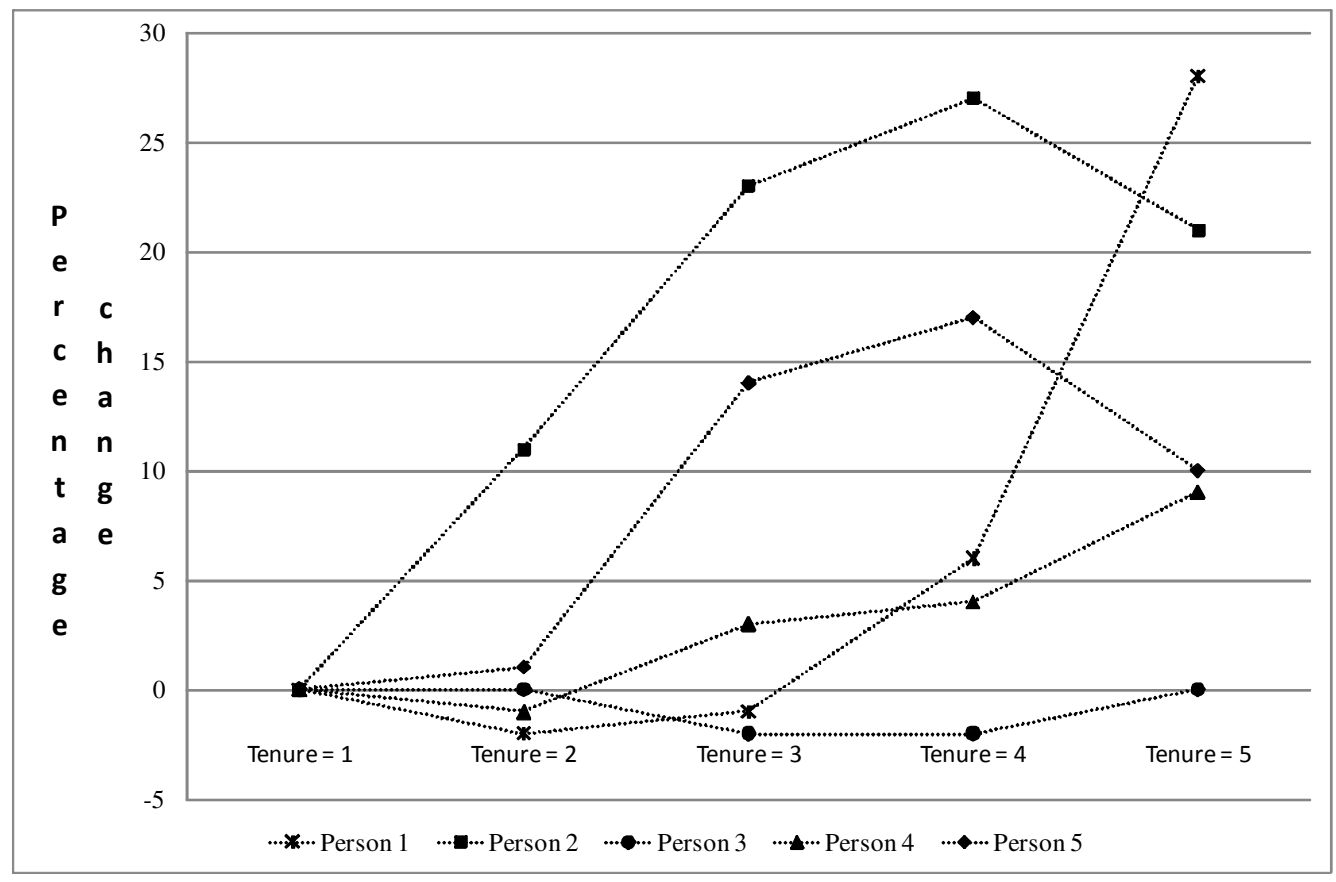

Figure 2: Five cases of individual earnings progression 
high performance through explicit bonus incentives. In addition, employees face career concern incentives which imply that current performance in part determines future compensation. ${ }^{3}$ The empirical importance of the contract's different components is illustrated in this subsection; a formal treatment will be given in the sections below.

The progression in base pay and bonus payments is presented in Table 1. Base pay increases with tenure, but the variance is only moderately amplified with tenure. Bonuses are somewhat different. Early in the career, the average bonus payment is 8 percent of average base pay, but bonuses increase relatively fast with tenure. Even if we focus on the bonuses paid out, the picture remains the same.

\begin{tabular}{lccc}
\hline Tenure & $\begin{array}{c}\text { Base pay } \\
\text { (Std. dev.) }\end{array}$ & $\begin{array}{c}\text { Bonus } \\
\text { (Std. dev.) }\end{array}$ & $\begin{array}{c}\text { Bonus|Bonus }>0 \\
\text { (Std. dev.) }\end{array}$ \\
\hline 1 & 66,557 & 5,318 & 9,101 \\
& $(21,615)$ & $(13,692)$ & $(16,544)$ \\
2 & 66,192 & 9,917 & 21,709 \\
& $(21,139)$ & $(23,228)$ & $(30,592)$ \\
& 69,089 & 13,518 & 31,285 \\
4 & $(20,445)$ & $(31,870)$ & $(42,634)$ \\
& 73,120 & 16,418 & 31,663 \\
5 & $(23,868)$ & $(44,488)$ & $(58,029)$ \\
& 75,176 & 22,159 & 42,735 \\
\hline \hline
\end{tabular}

Table 1. Progression in base pay and bonus payments

In addition to explicit incentives in the form of bonus payments, the employees are also motivated by career concern incentives which reward high performance employees with higher future earnings. Specifically, every spring the employees are subject to a performance appraisal. Close to 50 percent receive the score that they perform above expectation and these employees will be referred to as "top performers". The correlation between being a top performer and receiving a bonus is 0.23 , which establishes the link between performance and explicit incentives. Further, the correlation between being a top performer and earnings growth is 0.30 , which emphasizes the empirical importance of career concern incentives.

\footnotetext{
${ }^{3}$ The career-oriented incentives considered here transform high current performance into higher future bonus payments and base salaries. Thus, a potential promotion premium is indirectly incorporated. For a discussion of the promotion process and associated earnings progression, see Baker, Gibbs and Holmström (1994a,b), Gibbons and Waldman (1999a,b), and Frederiksen and Takáts (2011).
} 
In sum, the preliminary evidence provided in this section shows that the firm remunerates employees with a base pay and reward high performers through both explicit bonus incentives and career concern incentives. These findings guide the theoretical modelling of earnings progression in the next section.

\section{Theory}

In this section, I present a dynamic moral hazard model for earnings progression. The focus is on a common employment situation, where employees of unknown and heterogeneous productive ability work for a firm. The employees who become more productive with tenure as a consequence of on-the-job human capital acquisition are paid a base salary and face both explicit bonus incentives and career concern incentives. This model is capable of generating earnings dynamics which are sufficiently rich to match the empirical findings of the previous section.

\subsection{The model}

The model entails the contracting relation between a risk-neutral employer and a continuum of risk-neutral employees. Employer and employee form a principal-agent relationship. The employer is competing in a labor market characterized by public learning; i.e., information is symmetric, but imperfect. The employees are of unobserved heterogenous productive ability, but the ability distribution in the market is known. That is, employers and employees know that a proportion $(\mu)$ of the employees have a high productive ability $\theta_{H}$, and the rest $(1-\mu)$ have a low productive ability $\theta_{L}, \Theta=\left\{\theta_{L}, \theta_{H}\right\}$ and $0<\theta_{L}<\theta_{H}<1$. In this respect, some employees are systematically more productive than others. Further, the employer maximizes profits and the employee maximizes utility.

The model has two periods, $t=1,2$, and long-term contracts are not feasible because of limited commitment. Further, limited liability is assumed; thus, in the first period, the firm offers the employees a contract specifying a base payment $\left(w_{1} \geq 0\right)$ and a potential bonus $\left(b_{1} \geq 0\right)$. If the contract is accepted, the employee is hired. Subsequently, the employee chooses a level of effort $e_{t}=\{0, e\}$, which is unobserved by all other parties. At the end of the period, output is realized and observed by all. If the employee qualifies, a bonus is paid out. The second period starts with a revision of the beliefs about an employee's productive ability, which is based on the observed performance history. The new contract is adjusted accordingly. 
The employee accepts or rejects the new contract; and if accepted, a level of effort is chosen. Finally, the second period's output is observed and bonuses paid.

Employees are paid according to their expected productivity. The output $(y)$ is binary, and the employee may produce either a high or a low output. In the first period, the low output $\left(y_{1}\right)$ is normalized to zero. In the second period, low output $\left(y_{2}\right)$ is $\eta, \eta>0$. High first period output is $\overline{y_{1}}>0$, and in the second period it is $\overline{y_{2}}=\overline{y_{1}}+\eta$. The parameter $\eta$ reflects that an employee's productivity increases with tenure. This can be thought of as on-the-job human capital acquisition.

An employee of type $j, j=L, H$, produces high output with probability $\theta_{j} \in \Theta$. But when effort is exerted, i.e. $e_{t}=e$, which costs the worker a disutility of $c$, the probability of producing the high output increases by $\delta$. It is assumed that $\theta_{j}+\delta<1$ and that the productivity gain due to effort exceeds the cost of effort, i.e., $c \leq \delta \overline{y_{1}}$. Thus, it is efficient for the employee to exert effort. Further, to simplify notation $\bar{e}$ is used to denote that an employee exerts high effort in both periods, i.e. $\bar{e} \equiv\left\{e_{1}=e, e_{2}=e\right\}$.

Newly recruited employees have no performance history; as a result, the employer expects the individual to be of average productive ability, i.e., $E_{\Theta} \theta=\mu\left(\theta_{H}-\theta_{L}\right)+\theta_{L}$. Thus, when the employee exerts effort, the probability by which the employee is expected to produce a high output becomes:

$$
P_{1}=\operatorname{Pr}\left(\overline{y_{1}} \mid e_{1}=e\right)=\mu\left(\theta_{H}-\theta_{L}\right)+\theta_{L}+\delta .
$$

In subsequent periods, the beliefs concerning an employee's productive ability depend on the individual's performance history. This is because employers know that employees of high productive ability are more likely to produce a high output than employees of low productive ability i.e. $\theta_{H}+\delta>$ $\theta_{L}+\delta$. Thus, when an employee is observed producing a high output, the beliefs about expected productive ability are increased and the employee's reputation grows. Similarly, the beliefs get downgraded when low output is observed leading to a declining reputation. It follows that an employee who exerts effort in both periods and have a high performance in the first period is expected to produce a high output in the second period with probability:

$$
\overline{P_{2}}=\operatorname{Pr}\left(\overline{y_{2}} \mid \overline{y_{1}}, \bar{e}\right)=\frac{\left(\theta_{H}+\delta\right)^{2} \mu+\left(\theta_{L}+\delta\right)^{2}(1-\mu)}{P_{1}} .
$$

For an employee who also exerts effort in both periods but have a low first period output, the probability is:

$$
\underline{P_{2}}=\operatorname{Pr}\left(\overline{y_{2}} \mid \underline{y_{1}}, \bar{e}\right)=\frac{\left(1-\theta_{H}-\delta\right)\left(\theta_{H}+\delta\right) \mu+\left(1-\theta_{L}-\delta\right)\left(\theta_{L}+\delta\right)(1-\mu)}{1-P_{1}} .
$$


Thus, the gap in the second period performance probability due to reputation is:

$$
\Delta P=\overline{P_{2}}-\underline{P_{2}}=\frac{\mu(1-\mu)\left(\theta_{H}-\theta_{L}\right)^{2}}{P_{1}\left(1-P_{1}\right)}>0 .
$$

\subsection{The optimal contract}

The model is solved backwards to account for strategic behavior. The employee chooses a level of effort in each period to maximize utility. Because employers learn about an individual's productive ability from the first period output, the employee's second period utility depends on $y_{1}$. This implies that the employee exerts effort in the second period when:

$$
b_{2} \operatorname{Pr}\left(\overline{y_{2}} \mid y_{1}, \bar{e}\right)+w_{2}-c \geq b_{2} \operatorname{Pr}\left(\overline{y_{2}} \mid y_{1}, e_{1}=e, e_{2}=0\right)+w_{2},
$$

where the performance probability, $\operatorname{Pr}\left(. \mid y_{1},.\right)$ depends on the first period output. Thus, employees with different first period performances face different incentive constraints.

Naturally, the employee exerts effort when the gain in compensation exceeds the cost of effort. The left-hand side of (1) shows the utility when effort is exerted. The employee receives a bonus payment with probability $\operatorname{Pr}\left(\overline{y_{2}} \mid y_{1}, \bar{e}\right)$ and a base pay. This comes at a cost of $c$. The right-hand side shows the utility when no effort is exerted. Given the imposed assumptions: ${ }^{4}$

$$
b_{2}=c / \delta
$$

An employee's performance in the first period is disclosed and observed by the market. Thus, competition among prospective second-period employers implies that the contract accepted by the employee earns zero expected profits. So, expected productivity equals expected compensation:

$$
E\left(y_{2} \mid y_{1}, \bar{e}\right)-w_{2}-b_{2} \operatorname{Pr}\left(\overline{y_{2}} \mid y_{1}, \bar{e}\right)=0,
$$

or,

$$
w_{2}=\left(\overline{y_{1}}-c / \delta\right) \operatorname{Pr}\left(\overline{y_{2}} \mid y_{1}, \bar{e}\right)+\eta .
$$

Thus, the wage in the second period depends on first-period output $y_{1}$. In contrast, the size of the second-period bonus payment is independent of prior performance. However, the expected bonus payment, $B_{2}=b_{2} \operatorname{Pr}\left(\overline{y_{2}} \mid y_{1}, \bar{e}\right)$, does depend on the performance history because past performance determines the probability by which the employee is expected to receive a bonus

\footnotetext{
${ }^{4}$ Note that the workers and the firm have conflicting objectives implying that the incentive and the limited liability constraints bind.
} 
payment. It follows that expected earnings in the second period $\left(W_{2}\right)$ are determined in part by first-period output:

$$
\left.W_{2}\right|_{\left\{y_{1}, \bar{e}\right\}}=\overline{y_{1}} \operatorname{Pr}\left(\overline{y_{2}} \mid y_{1}, \bar{e}\right)+\eta,
$$

and that the gap in earnings $(R)$ due to employee reputation, which by definition equals an employee's career concern incentives, is:

$$
\begin{aligned}
R & =\left.W_{2}\right|_{\left\{\overline{y_{1}}, \bar{e}\right\}}-\left.W_{2}\right|_{\left\{\underline{y_{1}}, \bar{e}\right\}} ^{b_{2} \Delta P}+\underbrace{\left(\overline{y_{1}}-b_{2}\right) \Delta P}_{\text {Growth in expected bonus payments }} \\
& =\overline{y_{1}} \Delta P .
\end{aligned}
$$

This implies that career concern incentives are made up of higher future expected bonus payments because $b_{2}>0$ and $\Delta P>0$, and higher future base pay when $\overline{y_{1}}>c / \delta$.

Now the parameters of the first period can be determined. The employee's decision to exert effort takes into account that the output in this period affects the payoff in the second period. These career concerns add value to the first-period contract independent of the effort decision. But, by exerting effort the probability of high output, and thereby obtaining the second-period compensation premium $(R)$, is increased by $\delta$. Apart from this, the incentive problem is similar to the one in the second period, and the employee exerts effort if:

$$
b_{1} \operatorname{Pr}\left(\overline{y_{1}} \mid e_{1}=e\right)+w_{1}-c+\delta R \geq b_{1} \operatorname{Pr}\left(\overline{y_{1}} \mid e_{1}=0\right)+w_{1} .
$$

Hence, the first period bonus:

$$
b_{1}=c / \delta-R .
$$

It follows that the base pay in the first period is:

$$
w_{1}=\left(\overline{y_{1}}-c / \delta+R\right) \operatorname{Pr}\left(\overline{y_{1}} \mid e_{1}=e\right) .
$$

This completes the characterization of the optimal contract and leads to Lemma 1:

Lemma 1 The optimal contract is characterized by:

$$
\begin{aligned}
& b_{1}=c / \delta-\overline{y_{1}} \Delta P, \\
& b_{2}=c / \delta \\
& w_{1}=\left(\overline{y_{1}}(1+\Delta P)-c / \delta\right) P_{1}, \\
& \text { and }\left.w_{2}\right|_{\left\{y_{1}\right\}}=\left(\overline{y_{1}}-c / \delta\right) \operatorname{Pr}\left(\overline{y_{2}} \mid y_{1}, \bar{e}\right)+\eta .
\end{aligned}
$$




\subsection{Earnings progression}

In this section, the implications of the optimal contract for cross-sectional and individual earnings progression are investigated. The results show that earnings progression is determined by a trade-off between career concern incentives and explicit incentives besides being influenced by on-the-job human capital acquisition.

Earnings progression is a result of the joint movements in base pay and bonus. First, the growth in expected bonus payments can be expressed as follows:

$$
\left.B_{2}\right|_{\left\{y_{1}, \bar{e}\right\}}-\left.B_{1}\right|_{\left\{e_{1}=e\right\}}=b_{2}\left(\operatorname{Pr}\left(\overline{y_{2}} \mid y_{1}, \bar{e}\right)-P_{1}\right)+R P_{1},
$$

where $\left.B_{2}\right|_{\left\{y_{1}, \bar{e}\right\}}$ is the expected bonus for employees with first period performance $y_{1}$ who exert effort in both periods, and $\left.B_{1}\right|_{\left\{e_{1}=e\right\}}$ is the expected bonus in the first period if effort is exerted. The first part on the righthand side directly reflects the consequences of employee reputation. If the performance of an employee is high in the first period, this term is positive; when first-period performance is low, it is negative. The second part $\left(R P_{1}\right)$ is an unambiguously positive effect resulting from the substitution towards explicit incentives when the power of career concern incentives declines with tenure.

A similar decomposition can be made for base pay:

$$
\left.w_{2}\right|_{\left\{y_{1}\right\}}-w_{1}=\left(\overline{y_{1}}-b_{2}\right)\left(\operatorname{Pr}\left(\overline{y_{2}} \mid y_{1}, \bar{e}\right)-P_{1}\right)-R P_{1}+\eta .
$$

Base pay responds to reputation similarly to bonus payments, but the amplification constant differs, i.e., $\overline{y_{1}}-b_{1}$ instead of $b_{1}$. In addition, base pay growth is negatively affected by the declining career concern $\left(-R P_{1}<0\right)$ because an increasing part of an employee's compensation is paid in terms of explicit bonus payments when tenure increases. Finally, the anticipated positive effect on base pay growth due to on-the-job human capital acquisition is captured by $\eta$.

Combining the progression in bonus and base pay results in the following expression for earnings progression

$$
\begin{aligned}
\left.W_{2}\right|_{\left\{y_{1}, \bar{e}\right\}}-\left.W_{1}\right|_{\left\{e_{1}=e\right\}} & =\overline{y_{1}}\left(\operatorname{Pr}\left(\overline{y_{2}} \mid y_{1}, \bar{e}\right)-P_{1}\right)+\eta \\
& =k+\eta+R 1_{\left\{\overline{y_{1}}\right\}},
\end{aligned}
$$

where $\left.W_{2}\right|_{\left\{y_{1}, \bar{e}\right\}}$ is expected earnings for employees with first period performance $y_{1},\left.W_{1}\right|_{\left\{e_{1}=e\right\}}$ is expected earnings in the first period, and $k=$ 


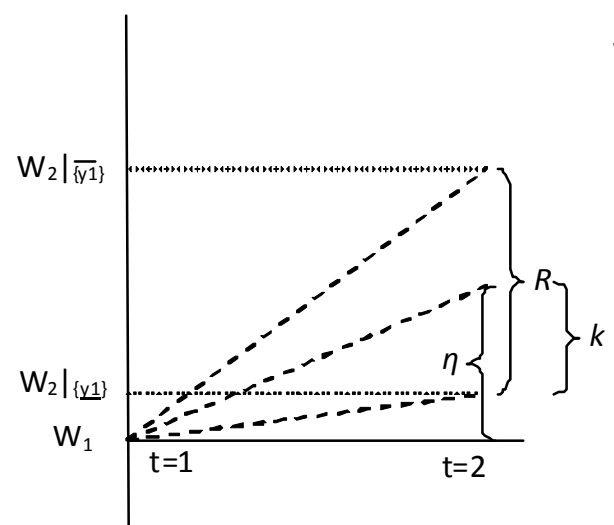

(a)

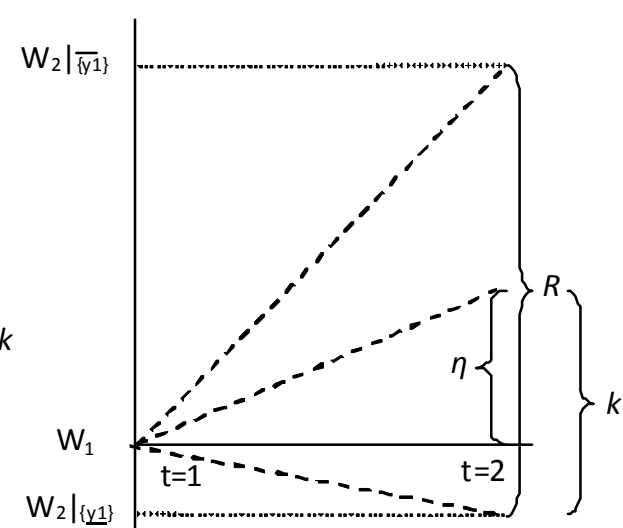

(b)

Figure 3: Earnings progression due to on-the-job human capital acquisition $(\eta)$, implicit career concern incentives $(R)$ and basic income growth $(k+\eta)$.

$\underline{P_{2}}-P_{1}=-\overline{y_{1}} \frac{\mu(1-\mu)\left(\theta_{H}-\theta_{L}\right)^{2}}{1-P_{1}}<0$ is a constant capturing the consequences of having low performance in the first period. Thus, high performance employees experience earnings growths of $k+\eta+R$, which equals the gains that follow from having a higher reputation and on-the-job human capital acquisition. In contrast, low performance employees have earnings progressions equal to $k+\eta$, which is positive when the human capital effect dominates the loss incurred by the lower reputation $(k+\eta>0)$ - but negative when the human capital effect is dominated $(k+\eta<0)$. The situation is illustrated in Figure 3 for the case of $P_{1}=\frac{1}{2}$.

It is important to point out that average earnings progression is determined exclusively by on-the-job human capital acquisition and not by incentives because:

$$
\left.W_{2}\right|_{\{\bar{e}\}}-\left.W_{1}\right|_{\left\{e_{1}=e\right\}}=\eta .
$$

Further, the heterogeneity in second period earnings is determined exclusively by how the firm sets incentives. Note that the optimal contract has three important features. First, it is optimal to let explicit bonus incentives increase with tenure to make up for the ongoing reduction in career concern incentives $\left(b_{1}<b_{2}\right)$. Second, optimal incentives are balanced such that total incentives (the sum of explicit bonus incentives and career concern incentives) are constant over an employee's career because $b_{1}+R=b_{2}$. Finally, if career concern incentives are sufficiently strong $(R>c / \delta)$, explicit incen- 
tives are not needed early in an employee's career. ${ }^{5}$ This trade-off between the different types of incentives determines their relative size and, thus, the spread in second period earnings:

$$
\left.W_{2}\right|_{\left\{\overline{y_{1}}, \bar{e}\right\}}-\left.W_{2}\right|_{\left\{\underline{y_{1}}, \bar{e}\right\}}=R .
$$

The findings of this section are summarized in Predictions 1 to 4 below.

Prediction 1 (Optimal incentive structure) Explicit bonus incentives increase with tenure. Total incentives (the sum of explicit bonus incentives and career concern incentives) are balanced over the career of an employee. Finally, if career concern incentives are sufficiently strong, explicit incentives are not part of the contract early in an employee's career.

Prediction 2 (Career concern incentives) Career concern incentives consist of higher future expected bonus payments and potentially of higher future base pay.

Prediction 3 (Individual income dynamics) High performance employees experience growth in earnings (due to an increase in reputation and on-the-job human capital acquisition). Low performance employees have positive earnings growth if the human capital effect dominates the loss incurred by the decline in reputation, and negative earnings growth otherwise.

Prediction 4 (Cross-section income dynamics) The cross-sectional mean of earnings increases with tenure (due to on-the-job human capital acquisition). The cross-sectional variance of earnings increases with tenure (as a consequence of incentives).

\section{Empirical analysis}

In this section the predictions of the theoretical model are examined empirically using the personnel records from a large bank. I find that both on-the-job human capital acquisition and incentives are empirically important for earnings progression. Combined they drive up both the mean and variance of cross-sectional earnings and cause individual earnings progression to be highly heterogenous. It is also established that the incentive structure

\footnotetext{
${ }^{5}$ The finding that explicit bonus incentives only serve as residual incentives is consistent with a recent paper by Frederiksen and Takáts (2011). They conclude that promotions and dismissals are at the top of the incentive hierarchy, and that explicit bonus incentives only enter the contract if other incentives prove insufficient.
} 


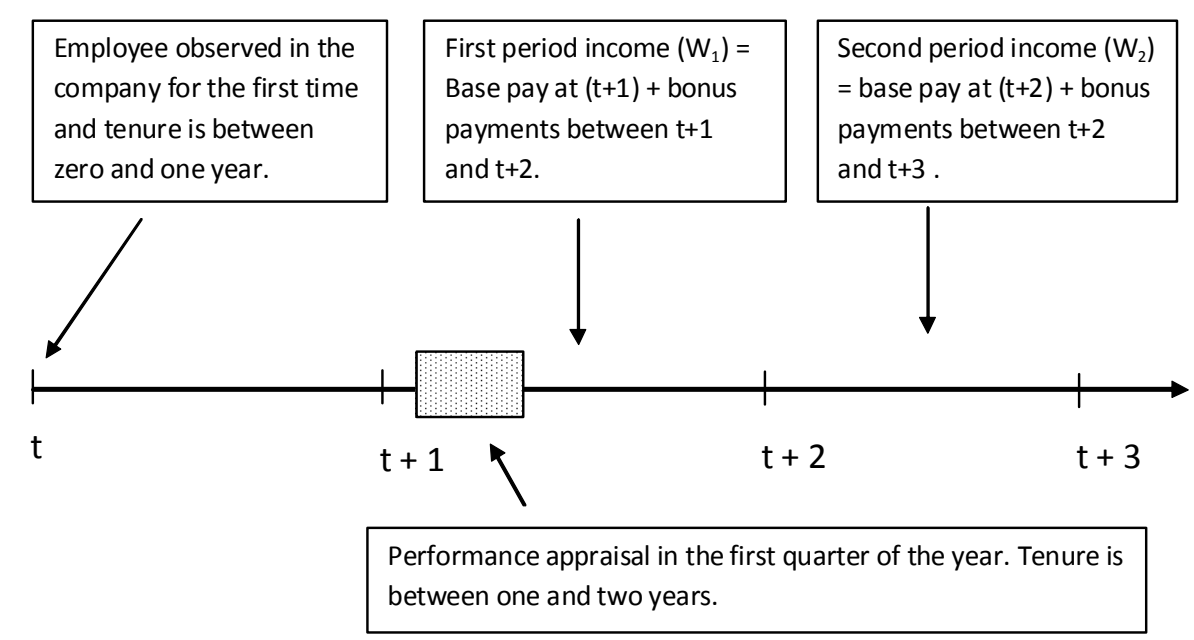

Figure 4: Sample selection and the timing of events

observed empirically is well aligned with the incentive structure derived from the model. Thus, the model's predictions are strongly supported by the data.

The stylized model presented above captures the employment situation where employee productivity at the time of recruitment is unknown and unobserved by both employer and employee, but it is known that the proportion $\mu$ is of high productive ability. In a real life setting we know that employee heterogeneity is much more complex because the degree of uncertainty about employee performance may vary across employee subgroups defined by education levels, job tasks etc. This additional heterogeneity may imply that the structural parameters in the theoretical model vary across employee subgroups. Formally, let $\Omega=\left\{\mu, \theta_{L}, \theta_{H}, \delta, \overline{y_{1}}\right\}$, then $R=R(\Omega)$. This implies that for $\tilde{\Omega} \neq \Omega$ it is likely that $R(\tilde{\Omega}) \neq R(\Omega)$; and, thus, identification of $R$ can only be obtained from subsamples where it is reasonable to assume that the numerical value of $R$ is the same. Nevertheless, the first set of estimates presented assume that $R$ is numerically the same for all employees. Subsequently, I use subsamples in which it is more likely that $R$ is constant across employees.

The empirical analysis which follows will stay as close to the theoretical model as possible. The model has two periods and assumes that employees have no prior employment history when they join the firm. For this reason, 
I focus the empirical analysis on early career earnings progression. ${ }^{6}$ The sample used in the analysis is selected as follows (see Figure 4). I took all employees observed in the data for the first time on January 1st in year t who stayed with the firm for at least three years, i.e. until January 1 st year $t+3$. This setup implies that the employee has been working for the firm for at least one year (and maximum two) before being subject to the performance appraisal, which takes place during the first quarter of year $t+1$. Thus, when an employee is evaluated, the firm has had ample time to actually observe the employee. Alternatively, using the performance evaluation available at the beginning of year $t$, the employees would have been with the firm less than one year and some only a few months. The sample consists of 1,242 employees.

\subsection{Identification}

In general, the influence of on-the-job human capital acquisition and incentives on earnings progression can be identified from the empirical counterpart of equation (3). The conditional earnings growth regression takes the following form

$$
\left(W_{2 i}-W_{1 i}\right)=k+\eta \cdot \Delta \text { tenure }_{i}+R \cdot 1_{\left\{\overline{y_{1}}\right\}}+\epsilon_{i},
$$

where $\epsilon_{i}$ is an error term. In the present context, however, where focus is on the first years of an employee's career, it is not possible to separately identify $\eta$ and $k$ from (5). Therefore, we need to identify $\eta$ from a different equation. Conveniently, equation (4) states that $W_{2}-W_{1}=\eta$; and, thus, a point estimate of $\eta$ can be obtained from the unconditional earnings growth regression

$$
\left(W_{2 i}-W_{1 i}\right)=\eta+\nu_{i}
$$

with $\nu_{i}$ being an error term.

\subsection{The incentive structure}

The first assessment of the theoretical model's empirical relevance is to investigate if there is alignment between the predicted incentive structure and the incentive structure observed empirically. Prediction 1 states that: i) explicit incentives increase with tenure, ii) total incentives are balanced, and iii) explicit incentives are absent early in the employment relation if career concern incentives are sufficiently strong.

\footnotetext{
${ }^{6}$ Extentions to a T-period setting are discussed below.
} 
First, the increase in explicit incentives with tenure is established using a t-test. It is important to remember that the test is $H_{0}: b_{1}=b_{2}$ against $H_{A}: b_{1}<b_{2}$. That is, the tested hypothesis is - the average bonus payment (actually paid out) in period one is equal to the average bonus payment (actually paid out) in period two - against the one-sided alternative. The data provides us with $b_{1}=13,299, b_{2}=18,776$, and $\Delta b=5,477$, which produces a p-value of 0.016 , and, thus, $H_{0}$ is rejected. Further, using the fact that some employees receive bonuses in both years, a similar test can be conducted for paired samples, which gives a p-value of 0 . Thus, there is clear evidence against $H_{0}$, which leads to the conclusion that explicit incentives are increasing with tenure.

Second, to establish if total incentives are balanced across the career requires a test of $\Delta b-R=0$. Using the subsample of employees receiving bonuses in both years, I estimate equation (5) and the regression $\Delta b=\kappa+\phi$, where $\kappa$ is a constant and $\phi$ an error term, to obtain point estimates of $\kappa$ and $R$. The test then becomes $H_{0}: \kappa-R=0$ against the two-sided alternative. Using the bootstrap to obtain standard errors on the statistic and subsequently performing a t-test results in a p-value of 0.839 . Thus, $H_{0}$ stating that incentives are balanced cannot be rejected.

Third, the last prediction that explicit incentives are used only when career concern incentives create too low incentives can only be established indirectly. Because all employees have bonus options and the estimate of $R$ is positive and significant, the data reveals that career concern incentives are insufficient to incentivize employees. For this reason, the contract includes explicit incentives.

In sum, there is clear evidence for the fact that explicit incentives increase with tenure and for sizeable career concern incentives. The relative size of these incentives imply that total incentives (the sum of career concern and explicit incentives) are balanced over the employees' careers. Further, it is also clear that it is necessary to combine explicit incentives and career concern incentives to incentivize employees, which underlines the complexity of motivating employees. Combined, these findings provide support for Prediction 1.

\subsection{Earnings progression}

The nature of earnings progression can be established by estimation of equation (5) and equation (6). The first column of Table 2 shows the estimation results for equation (5). The highly significant point estimate of $R=6,165$ implies that employees with high first period performance have earnings growth which is 9.48 percent higher than employees with a low first period 
performance. This emphasizes the economic significance of career concern incentives. Estimating equation (6) reveals that $\eta=6,816(S E=632)^{7}$; and, hence, the contribution from on-the-job human capital acquisition to earnings progression is 10.5 percent. Combined the results imply that low performers have earnings growth of 6.1 percent $(\eta+k=3,962)$ while top performers have earnings progressions close to 15.6 percent $(\eta+k+R=10,127)$. Thus, both the the mean and the variance of cross-sectional earnings increase with tenure, and individual earnings progression is highly heterogeneous. This provides empirical support for both Prediction 3 and Prediction 4.

\begin{tabular}{|c|c|c|c|c|c|c|}
\hline & \multicolumn{2}{|c|}{ Earnings growth } & \multicolumn{2}{|c|}{ Base pay growth } & \multicolumn{2}{|c|}{ Bonus growth } \\
\hline & $\begin{array}{l}\text { Beta } \\
\text { (SE) }\end{array}$ & $\%$ & $\begin{array}{l}\text { Beta } \\
\text { (SE) }\end{array}$ & $\%$ & $\begin{array}{l}\text { Beta } \\
\text { (SE) }\end{array}$ & $\%$ \\
\hline Constant $(\eta+k)$ & $\begin{array}{c}3,962^{* * *} \\
(854)\end{array}$ & 6.09 & $\begin{array}{c}2,829 * * * \\
(251)\end{array}$ & 4.35 & $\begin{array}{l}1,132 \\
(806)\end{array}$ & 1.74 \\
\hline High performance in period $1(R)$ & $\begin{array}{c}6,165^{* * *} \\
(1,255)\end{array}$ & 9.48 & $\begin{array}{c}29 \\
(368)\end{array}$ & 0.04 & $\begin{array}{c}6,136 * * * \\
(1,184)\end{array}$ & 9.44 \\
\hline
\end{tabular}

Note: Significant coefficients at the $1 \%$ level are indicated with ${ }^{* * *}$, at the $5 \%$ level with ${ }^{* *}$ and at the $10 \%$ level with *. The number of observations in all regressions is 1242 . Percentage growth is with first year income as base.

Table 2. Regressions for growth in earnings, base pay and bonus payments.

The dynamics in the underlying earnings components are shown in column two and three of Table 2, where conditional regressions are presented for respectively base pay and bonus growth. First, base pay growth is independent of performance and is at a level of four percent. Second, the growth in expected bonus payments depends on performance; and there is no systematic growth due to tenure. Thus, expected earnings growth splits neatly into two components, i.e., systematic growth in base pay and performance-related growth in expected bonus payments.

Table 2 also provides insights into the structure of career concern incentives, which allows for testing of prediction 2 . In equation (2) it is established that career concern incentives follow from future gains in bonus payments and potential gains in base pay. In line with the prediction, Table 2 shows that career concern incentives, which equals 9.48 percent of first year earnings, are predominantly due to higher bonus payments (9.44 percent) and not due to base pay growth (0.04 percent).

\footnotetext{
${ }^{7}$ Keeping the discussion related to Figure 3 in mind, this result is in line with the theoretical predictions. The proportion of high performers is 0.463 and thus $(\eta+k)-k=$ $3,962+P_{1} R=3,962+0.463 * 6,165=6,816$.
} 


\subsection{Subgroup heterogeneity}

The results above ignore the potential employee heterogeneity which is due to differences in education and other observable characteristics. For instance, it is to be expected that university graduates are more productive than less educated employees, which can be thought of as variation in $y$. But, the distribution of unobserved productive ability $\left(\mu, \theta_{H}, \theta_{L}\right)$ may also vary by education, see Spence (1973). The data provides some evidence for this. First, average income is substantially higher (42 percent) for university graduates. It is also the case that 61 percent of university graduates become top performers, whereas only 42 percent of the less educated receive this rating. Hence, there is reason to expect that $\Omega$ (and thus $R(\Omega)$ ) vary by education.

Ten percent of the employees have university degrees, and the remaining employees are classified as not having a university degree. ${ }^{8}$ In Table 3 a set of regressions is presented which sheds light on the differences in pay progression across education groups. The first model replicates the results from Table 2. In model 2 a dummy for having a university degree is included, and the point estimate is positive and significant, reflecting higher pay progression for university graduates. Model 3 includes an interaction between performance and the university dummy. Now the university dummy turns insignificant, but the interaction effect is positive and significant. Hence, the higher income progression of university graduates established in model 2 is not a result of their benefitting from higher basic earnings progression, but rather because high performance is more highly rewarded for this group of employees.

A natural concern related to the results in model 3 is that university employees and other employees are assigned to different types of jobs. It is possible to account for this by grouping employees by job function: Central staff, business units and market functions, and dummies for these are included in model 4. The regression reveals several interesting results. First, earnings progression is positive for employees without university degrees $(2,080, S E=$ $1,126)$, but it is significantly lower and negative for university graduates $(2,080-5,173=-3,093)$. Second, the performance effect is insignificant for employees without a university degree $(988, S E=1,248)$, but is highly significant for university graduates (interaction effect $=11,830, S E=3,853$ ). These results reveal that employees with different levels of education are perceived differently by the market, and, thus, they are subjected to different

\footnotetext{
${ }^{8}$ Information on education is available for 77 percent of the sample. Statistical tests reveal that the group with missing information on education and the group with less than a university degree are statistically similar; and, consequently, they are treated as one group. The presented results prevail even when excluding individuals without educational information.
} 
employment contracts. This result prevails even when taking into account that employees with different types of education are allocated different jobs in the organization.

\begin{tabular}{lcccc}
\hline & $(1)$ & $(2)$ & $(3)$ & $(4)$ \\
\hline Constant & $3,962^{* * *}$ & $3,605^{* * *}$ & $4,282^{* * *}$ & $2,080^{*}$ \\
& $(854)$ & $(867)$ & $(883)$ & $(1,126)$ \\
High performance in period 1 & $6,165^{* * *}$ & $5,881^{* * *}$ & $4,364^{* * *}$ & 988 \\
& $(1,255)$ & $(1,259)$ & $(1,322)$ & $(1,248)$ \\
Less than university & & - & - & - \\
& & & & $-5,173^{*}$ \\
University degree & & $(2,051)$ & $(3,193)$ & $(2,969)$ \\
& & & $14,973^{* * *}$ & $11,830^{* * *}$ \\
University degree & & $(4,152)$ & $(3,853)$ \\
$\quad *$ High performance in period 1 & & & & - \\
Central staff & & & & 1,510 \\
& & & & $(1,254)$ \\
Business units & & & $27,050^{* * *}$ \\
& & & & $(1,957)$ \\
Market functions & & & & \\
& & & & \\
\hline \hline
\end{tabular}

Note: The left hand side variable is income growth between period 1 and 2 . Significant coefficients at the $1 \%$ level are indicated with $* * *$, at the $5 \%$ level with ** and at the $10 \%$ level with $*$. The number of observations in all regressions is 1242 .

Table 3. Earnings progression across education groups

A further investigation into heterogeneity can be made through equation (6). Up to this point an identifying assumption has been that human capital is acquired at the same rate for all employees, i.e., that $\eta$ is the same across employees. Hence, it is interesting that when earnings growth is regressed on a constant, a university dummy and job function, an insignificant point estimate on the university dummy $(2,049, S E=1,913)$ is obtained. This rejects that $\eta$ is significantly different between university graduates and employees with less education. Thus, the identifying assumption is supported in the present sample.

\subsection{Extensions}

The stylized model presented in section 3 can straightforwardly be extended to a T-period model which allows for broader performance signals. For instance, in a three-period model both performance in period 0 and period 1 may influence earnings progression between periods 1 and 2 . It may also be the case that consistently high performance may amplify earnings progression. 


\begin{tabular}{|c|c|c|c|}
\hline & (1) & (2) & (3) \\
\hline Constant & $\begin{array}{r}3,359 * * \\
(1,662)\end{array}$ & $\begin{array}{l}3,161^{*} \\
(1,664)\end{array}$ & $\begin{array}{r}, 347^{* *} \\
(1,677)\end{array}$ \\
\hline $\begin{array}{l}\text { High performance in } \\
\text { period } 1\end{array}$ & $\begin{array}{r}4,680 * * \\
(2,150)\end{array}$ & $\begin{array}{r}4,477^{* *} \\
(2,149)\end{array}$ & $\begin{array}{l}4,163^{*} \\
(2,177)\end{array}$ \\
\hline $\begin{array}{l}\text { High performance in } \\
\text { period } 0\end{array}$ & & $\begin{array}{l}9,994^{*} \\
(5,988)\end{array}$ & $\begin{array}{c}624 \\
(11,885)\end{array}$ \\
\hline $\begin{array}{l}\text { High performance in } \\
\text { both periods }\end{array}$ & & & $\begin{array}{r}12,559 \\
(13,759) \\
\end{array}$ \\
\hline
\end{tabular}

Table 4. Earnings progression and performance

To investigate this issue further, I extended the selection criteria of Figure 4 to three periods, which reduces the sample size to 500 observations. The results of the analysis is presented in Table 4 . In the first model only performance in period 1 is used to explain earnings growth between periods 1 and 2. This model is similar to the one presented in Table 2 but uses a reduced sample. The performance effect is positive and significant and at a level close to the result presented earlier. Model 2 includes dummies for performance in periods 0 and 1 and shows that both variables are positive and significant at the 10 percent level. However, with an interaction effect in performance (model 3) only the performance effect of period 1 prevails. These results show that there may be scope for more elaborate performance signals, but it is impossible to infer their effects with acceptable precision from the present sample. Future research should shed light on this issue.

\section{Conclusion}

Earnings progression varies substantially across newly recruited employees. In this article, I have used a dynamic moral hazard model which incorporates explicit short-run incentives, career concern incentives and on-the-job human capital acquisition to shed new light on the mechanisms that lead to the sizeable differences in earnings progression. The presented model, which is in line with a large body of existing theoretical literature, points at career concerns incentives playing a key role for the way earnings progress. Nevertheless, only limited empirical evidence supports this prediction. For this 
reason, the empirical findings of this paper, which emphasizes that career concerns incentives are sizeable and generally present in the labor market, provide important new evidence in support for this line of research.

Another important finding is that it is essential to acknowledge the interplay between performance and incentives to understand the earnings process. For example, performance is important for short-run volatility because high performance may lead to bonus payments. Further, performance manifests itself more permanently when career concern incentives are present because the performance history is important for remuneration. In fact, individual performance may in part determine both future bonus payment and future base pay.

To conclude, the article offers some new perspectives on earnings progression. While the analytical framework can easily be extended both theoretical and empirically, the data available for the analysis impose constraints. Consequently, it is clear that longer panels of performance and pay may shed additional light on the earnings process. It would also be interesting to obtain a better understanding of how important variation in employee and job heterogeneity is for the way contracts are set - because in turn it determines the earnings process. In this way this paper paves the way for future research.

\section{References}

[1] Abowd, J. M., and D. Card (1989) "On the covariance structure of earnings and hours changes", Econometrica, 57, pp. 411-445.

[2] Altonji, J. G. and C. R. Pierret (2001) "Learning and statistical discrimination", The Quarterly Journal of Economics, 116, pp. 313-350.

[3] Baker, G. P., M. Gibbs and B. Holmström (1994a) "Subjective performance measures in optimal incentive contracts", The Quarterly Journal of Economics, 109, pp. 881-919.

[4] Baker, G. P., M. Gibbs and B. Holmström (1994b) "The wage policy of the firm", The Quarterly Journal of Economics, 109, pp. 921955.

[5] Becker, G. S. (1964) "Human capital", 1st ed., New York: the National Bureau of Economic Research.

[6] Borland, J. (1992) "Career concern: Incentives and endogenous learning in labour markets", Journal of Economic Surveys, 6, pp. 251-270. 
[7] Chevalier, J., and G. Ellison (1999) "Career concern of mutual fund managers", The Quarterly Journal of Economics, 114, pp. 389-432.

[8] Deaton, A. (1992) "Understanding consumption", Clarendon Press, Oxford.

[9] Farber, H. S., and R. S. Gibbons (1996) "Learning and wage dynamics", The Quarterly Journal of Economics, 111, pp. 1007-1047.

[10] Fama, E. (1980) "Agency problems and the theory of the firm", The Journal of Political Economy, 88, pp. 288-307.

[11] Frederiksen, A., and E. Takáts (2011) "Promotions, dismissals and employee selection: Theory and evidence, forthcoming in: Journal of Law, Economics and Organization.

[12] Gibbons, R. S., and K. J. Murphy (1992) "Optimal incentive contracts in the presence of career concern: theory and evidence", The Journal of Political Economy, 100, pp. 468-505.

[13] Gibbons, R. S., and M. Waldman (1999a) "A theory of wage and promotion dynamics inside firms", The Quarterly Journal of Economics, 114, pp. 1321-58.

[14] Gibbons, R. S., and M. Waldman (1999b) "Careers in organizations: theory and evidence" in Handbook of Labor Economics, Ch 36, ed. by O. Ashenfelter and D. Card, Elsevier.

[15] Gibbons, R. S., and M. Waldman (2003) "Wage and promotion dynamics inside firms", Journal of Labor Economics, 24, pp. 59-107.

[16] Holmström, B. (1979) "Moral hazard and observability", Bell Journal of Economics, 9, pp. 74-91.

[17] Holmström, B. (1982a) "Moral hazard in teams", Bell Journal of Economics, 13, pp. 324-40.

[18] Holmström, B. (1982b) "Managerial incentive problems - A dynamic perspective", in Essays in Economics and Management in Honor of Lars Wahlbeck. Helsinki: Swedish School of Economics.

[19] Holmström, B. (1999) "Managerial incentive problems: A dynamic perspective", Review of Economic Studies, 66, pp. 169-182. 
[20] Irlenbusch, B., and D. Sliwka (2006) "Career concern in a simple experimental labour market", European Economic Review, 50, pp 147170.

[21] Koch, A. K., A. Morgenstern and P. Raab (2009) "Career concern incentives: An experimental test", Journal of Economic Behavior and Organization, 72, pp. 571-588.

[22] Lange, F. (2007) "The speed of employer learning", Journal of Labor Economics, 25, pp.1-35.

[23] Lillard, L. A., and Y. Weiss (1979) "Components of variation in panel earnings data: American scientists, 1960-70", Econometrica, 47, pp. $437-454$.

[24] Lillard, L. A., and R. J. Willis (1978) "Dynamic aspects of earnings mobility", Econometrica, 46, pp. 985-1012.

[25] MaCurdy, T. E. (1982) "The use of time series processes to model the error structure of earnings in a longitudinal data analysis", Journal of Econometrics, 18, pp. 83-114.

[26] Meghir, C., and L. Pistaferri (2004) "Income variance dynamics and heterogeneity", Econometrica, 72, pp. 1-32.

[27] Mirrlees, J. (1974) "Notes on welfare economics, information, and uncertainty" in Essays on economic behavior under uncertainty, M. Balch, D. McFadden and S. Wu, eds., North Holland, Amsterdam, pp. 243-258.

[28] Mirrlees, J. (1976) "The optimal structure of incentives and authority within an organization", Bell Journal of Economics, 7, pp. 105-131.

[29] Spence, A. M. (1973). "Job market signaling", Quarterly Journal of Economics, 87, pp. 355-374. 